\title{
A Relação Interprofissional Entre Os Profissionais de Saúde em um Hospital Escola do Sul de Minas Gerais
}

\author{
Monteiro, Natália Fechus; Silva, Karina Maia da; Pinto, José Henrique Pereira \\ Faculdade de Medicina de Itajubá — nafechus@hotmail.com
}

Introdução: na ciência da saúde, as conquistas se deram por descobertas de agentes patogênicos, fisiopatologia das doenças, medicamentos e meios diagnósticos cada vez mais sofisticados, mas a maior conquista - ainda almejada - está relacionada com a ciência humana. Mais importante que pesquisar a doença do paciente, é estabelecer a saúde em seu sentido amplo de bem-estar físico, mental e social. a Humanização é a melhor proposta para garantir ao paciente o que lhe é direito, não só como cliente da saúde, mas como ser humano. com base nesta proposta é essencial uma interação eficaz entre profissionais de saúde e o paciente. Objetivos: o objetivo deste trabalho é caracterizar o nível de satisfação do relacionamento interprofissional entre os profissionais de saúde a fim de apresentar os princípios de humanização já alcançados e identificar os princípios que ainda se encontram deficientes. Métodos: a pesquisa qualitativa utilizou técnica de entrevistas semiestruturadas com base no referencial da análise de conteúdo em sua vertente temática através do relato dos próprios membros da equipe multiprofissional, escolhidos aleatoriamente e convidados a participarem da pesquisa. Resultados: Dentre os principais resultados, observou-se ineficiência da comunicação entre os profissionais, pouca abrangência da Política Nacional de Humanização junto aos trabalhadores, além de discórdias entre os profissionais e métodos possíveis para uma melhor interação da equipe visando benefício ao paciente. Conclusão: Os dados encontrados demonstram a necessidade de se fomentar o protagonismo desses sujeitos, tornando visível a gestão que os trabalhadores da saúde fazem do seu próprio processo de trabalho, bem como aprimorar mecanismos de gestão participativa com a ampliação de uma relação transversal entre os sujeitos envolvidos no cuidado do doente, numa perspectiva em que todos sejam corresponsáveis pelos rumos da atenção prestada.

Monteiro, Natália Fechus; Silva, Karina Maia da; Pinto, José Henrique Pereira. A Relação Interprofissional Entre Os Profissionais de Saúde em um Hospital Escola do Sul de Minas Gerais. In: Anais do Congresso Internacional de Humanidades \& Humanização em Saúde [= Blucher Medical Proceedings, num.2, vol.1]. São Paulo: Editora Blucher, 2014. ISSN 2357-7282

DOI 10.5151/medpro-cihhs-10658 